\title{
Application and Selection of the Reagent to Neutralize Hydrogen Sulfide and Light Methyl-, Ethyl- Mercaptans in Oil
}

\author{
Tatyana Kuryakova $^{1, *(D)}$, Larisa Mezhueva ${ }^{2}$ (D), Bykov Artem ${ }^{2}$ (D), Valerii Popov ${ }^{2}$ (D), \\ Galina Sidorenko 2 (D) \\ 1 Federal State Budgetary Educational Institution of Higher Education "National University of Oil and Gas (Gubkin \\ University)", branch in Orenburg, 20, st. Yunykh Lenintsev, Orenburg, 460047, Russia; kwan111@ yandex.ru; \\ 2 Federal State Budgetary Educational Institution of Higher Education Orenburg State University, 13, prospect Pobedy, \\ Orenburg, 460018, Russia; olgakvan81@gmail.com; \\ * Correspondence: kwan111@yandex.ru;
}

Scopus Author ID 57090891800

Received: 13.02.2020; Revised: 15.05.2020; Accepted: 20.05.2020; Published: 1.06.2020

\begin{abstract}
The choice of an effective neutralizer for a particular field is made on the basis of laboratory studies and pilot tests. A number of laboratory tests were conducted to select a hydrogen sulfide neutralizer for oil at the loading point of the Borodino field. The studies were carried out according to the standard method of the "bottle roll test" at $45^{\circ} \mathrm{C}$ with various amounts of the reagent-neutralizer by bubbling oil and reagents. Laboratory tests for the selection of effective reagents-neutralizers were carried out by modeling the process of collecting and preparing oil at the loading point of the Borodino field in two stages. The results of laboratory research allowed us to choose the most optimal neutralizer, set its flow rate, and temperature of oil heating. In addition, t influence of the place where the reagent neutralizer is introduced into degassed oil is studied. The laboratory tests made it possible to select the best neutralizer Desoulfon-SNPCH-1200, to determine its minimum specific consumption and the temperature of heating oil. The application of this reagent-neutralizer will allow doing the effective oil preparation at the loading point of the Borodino field. The amount of Desoulfon-SNPCH-1200 needed to neutralize the mercaptans depends on their content in oil and the required degree of reduction.
\end{abstract}

Keywords: oil; hydrocarbons; neutralizers; laboratory test; reagent.

(C) 2020 by the authors. This article is an open-access article distributed under the terms and conditions of the Creative Commons Attribution (CC BY) license (https://creativecommons.org/licenses/by/4.0/).

\section{Introduction}

One of the most important processes related to the extraction, collection, and transportation of marketable oil to consumers - oil refineries - in the preparation of oil in the field [1-5]. The use and selection of the most effective reagents - neutralizers to strip hydrocarbons from mercaptans can improve the quality of marketable oil and improve the environmental situation in fields [6-7].

New stringent requirements for the safe transportation and storage of petroleum raw materials, the quality of petroleum products and the transition to high requirements for fuels according to the Euro-4 and Euro-5 standards encourage oil companies to develop and implement new, modern technologies aimed at reducing the content of toxic and corrosive sulfur compounds of oil-hydrogen sulfide and mercaptans[8-11]. 
The toxic substances contained in the oil, hydrogen sulfide and mercaptans, are easily volatile, have an unpleasant pungent smell, and must be completely removed from the product for environmentally safe transportation and storage [12-13].

Sulfur in the Borodino oil field is mainly represented by light mercaptans, so it became possible to remove hydrogen sulfide and mercaptans using reagents-neutralizers. When using neutralizers, a chemical interaction occurs, which results in the formation of inert low-toxic compounds [14-19].

At the same time, neither the reagent itself nor the reaction products should be corrosive and degrade the quality of the raw material. Reagents-neutralizers are introduced into the raw material in small quantities $(1-3 \mathrm{~kg} / \mathrm{t})$. The main obstacle to the widespread use of sinks is their high cost. Therefore, it is important to select highly effective, low-toxic, cheap, and stable reagents for storage [20-22].

A wide range of reagents available on the market has shown that the choice of an effective neutralizer for a particular field is made on the basis of laboratory studies and pilot tests. Qualitative evaluation of neutralizers is made on the basis of chemical experiments [23-25].

Laboratory tests allow us to evaluate the comparative effectiveness of reagents. The obtained data are used to determine the flow rate of the neutralizer and the parameters of the oil preparation process for a specific field.

Specific consumption and adjustments to the technological parameters of oil preparation are set in the process of field testing.

Based on the above, several laboratory tests were conducted to select a hydrogen sulfide neutralizer for oil at the loading point of the Borodino field [26-27].

\section{Materials and Methods}

Laboratory studies of 2016 on the residual content of light mercaptans at the loading point revealed an excess of the mass fraction of methyl- and ethyl- mercaptans in the prepared oil of the Borodino field, the results can be found in figure 1.

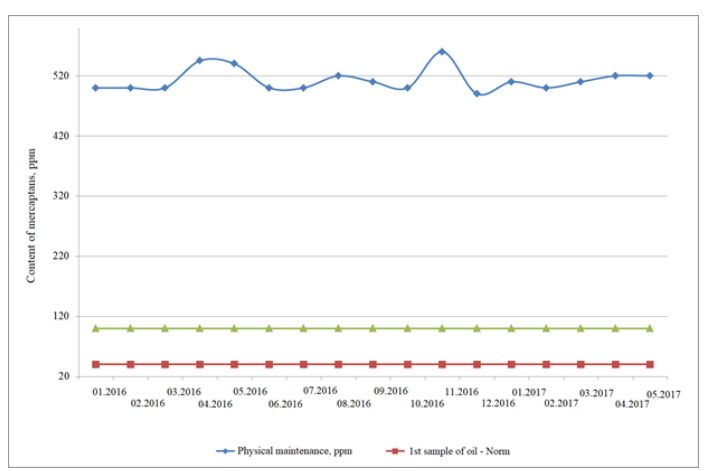

Figure 1. The residual content of light mercaptans in prepared oil in 2016-2017.

Due to the high content of residual mercaptans in oil at the loading point of the Borodino field in 2016, additional laboratory studies were carried out to make a reasonable choice of the most effective neutralizer. A comparative analysis of tested samples was conducted. The list of neutralizers is presented in Table 1, their chemical properties - in Table 2.

The studies were carried out according to the standard method of the "bottle roll test" at $45^{\circ} \mathrm{C}$ with various amounts of the reagent-neutralizer by bubbling oil and reagents. 
Laboratory tests for the selection of effective reagents-neutralizers were carried out by modeling the process of collecting and preparing oil at the loading point of the Borodino field in two stages.

The effectiveness of the use of reagents-neutralizers was determined by the method of measuring the initial and residual contents of mercaptans as the hydrogen sulfide content in the tested oil of the Borodino field does not exceed the established standards [8].

The first stage determined the amount of reagent required to reduce the mass fraction of mercaptans in oil to levels below $100 \mathrm{ppm}$. The consumption ratio was considered equal to 2.5 $\mathrm{mg} / \mathrm{g}$.

The specific consumption of the reagent was $1.2 \mathrm{~kg} / \mathrm{t}$ in stripping the oil at the loading point on theoretical values; the maximum time of the effective interaction of reagents with mercaptans was 24 hours. The reagent was mixed with oil using a laboratory shaker [21].

\section{Results and Discussion}

Given the existing oil preparation technology, which consists of sludging and heating raw oil, the use of neutralizers to remove mercaptans and sulfur compounds is the most effective measure in the current situation. The selection of neutralizers is largely determined by the properties of extracted products, including one of the most important qualities of the reagent the absence of formaldehyde in it [28-29].

The results of studies on the reagents are presented in Table 3. According to the results, it can be concluded that the reagents of Desoulfon-SNPCH-1200, INS-1, and Reaton-21-2 were effective for stripping oil of the Borodino field, the consumption ratios of which were minimal - from 2.3 to $2.5 \mathrm{~g} / \mathrm{g}$. The main amount of mercaptans was neutralized within the first 4-6 hours when all the studied reagents were added. During the specified time range, the reduction of the mass fraction of mercaptans below 100 ppm was achieved only with the addition of reagents Desoulfon-SNPCH-1200 and Reaton-21-2.

The amount of Desulfone-SNPCH-1200 required to neutralize mercaptans depends on their content in the system and the necessary degree of their reduction. The usual treatment ratio is 4-5ppm of Desulfone-SNPCH-1200 per 1 ppm of mercaptans.

Desulfone-SNPCH-1200 additionally has a protective anti-corrosion effect in hydrogen sulfide-containing environment. The protective effect at the dosage of $30 \mathrm{~g} / \mathrm{m}^{3}$ of liquid is 60 $70 \%$. The reagent also has the properties of bactericide that suppresses the growth of sulfatereducing bacteria.

Desulfone-SNPCH-1200 does not adversely affect the oil preparation process, quality of commercial oil, and does not contain organochlorine compounds.

At the same time, dosing of reagents Darsan and sulfanox Did not allow for a mass fraction of mercaptans in oil less than $100 \mathrm{ppm}$.

Table 1. Neutralizers.

\begin{tabular}{c|c}
\hline Neutralizer & Manufacturer \\
\hline Reagent DARSAN (mark N) & LLC ANK, Ufa \\
Specifications 2458-003-50771613-2004, changes NN 1, 2 & LLC Reaton, Kazan \\
\hline Reagent for hydrogen sulfide and mercaptans stripping & \\
Reaton-21-2 & LLC Mirrico, Kazan \\
\hline Hydrogen sulfide and mercaptan neutralizer Sulfanox \\
Specifications 2458-067-94296805-2010
\end{tabular}




\begin{tabular}{c|c}
\hline Neutralizer & Manufacturer \\
\hline TУ 2456-003-84449478-2009 & \\
\hline Desoulfon-SNPCH-1200 & "NIIneftepromchim" JSC \\
Specifications 2458-006-66875473-2013 & \\
\hline
\end{tabular}

Table 2. Experimental data from laboratory studies on the content of mercaptans in the original oil at $545 \mathrm{ppm}$.

\begin{tabular}{c|c|c|c|c}
\hline \multirow{2}{*}{ Reagent } & \multicolumn{4}{|c}{ The residual content of mercaptans, ppm } \\
\cline { 2 - 5 } & $\mathbf{1 ~ h}$ & $\mathbf{2 ~ h}$ & $\mathbf{4 ~ h}$ & $\mathbf{2 4} \mathbf{~ h}$ \\
\hline DARSAN (mark N) & 320 & 280 & 260 & 250 \\
\hline Reaton-21-2 & 200 & 120 & 100 & 50 \\
\hline Sulfanox & 260 & 240 & 200 & 150 \\
\hline INS-1, & 200 & 150 & 125 & 52 \\
\hline Desoulfon-SNPCH-1200 & 140 & 100 & 60 & 40 \\
\hline
\end{tabular}

Table 3. Experimental data on the refinement of the specific consumption of reagents with the content mercaptans in the original oil at $545 \mathrm{ppm}$.

\begin{tabular}{|c|c|c|c|c|c|}
\hline \multirow[t]{2}{*}{ Reagent } & \multirow{2}{*}{$\begin{array}{c}\text { Specific } \\
\text { consumption } \\
\text { of reagent, } \\
\mathrm{kg} / \mathrm{t}\end{array}$} & \multicolumn{2}{|c|}{$\begin{array}{l}\text { The residual content of mercaptans, } \\
\text { ppm }\end{array}$} & \multicolumn{2}{|c|}{ Consumption ratio } \\
\hline & & $4 \mathrm{~h}$ & $24 \mathrm{~h}$ & $4 \mathrm{~h}$ & $24 \mathrm{~h}$ \\
\hline Reaton-21-2 & 1.13 & 184 & 84 & 3.1 & 2.4 \\
\hline $\begin{array}{c}\text { Desoulfon- } \\
\text { SNPCH-1200 }\end{array}$ & 1.08 & 87 & 54 & 2.3 & 2.2 \\
\hline INS-1 & 1.4 & 220 & 142 & 3.9 & 3.5 \\
\hline
\end{tabular}

The next stage of selecting a neutralization reagent was the reduction of the mass fraction of mercaptans in oil to $80 \mathrm{ppm}$ and the determination of the actual consumption factor of the three most efficient samples.

The results showed that the consumption ratios of the samples were of close value. However, it should be noted that when oil is water cut less than $10 \%$, the reaction products of the interaction between the reagent-neutralizer and mercaptans precipitated, so in order to avoid the formation of sediment, $10 \%$ of freshwater was poured into the oil: figures 2 and 3 present data of visual observations [26-28].

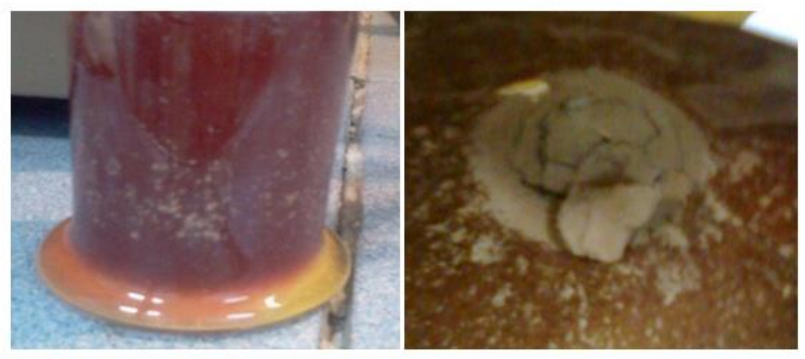

Figure 2. Sedimentation of the products of the reaction between the neutralizer and organosulfur compounds in

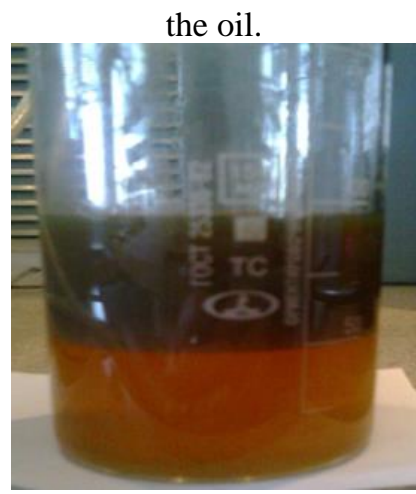

Figure 3. Result of the reaction between the neutralizer and organosulfur compounds with the addition of water. 
The results of laboratory research allowed us to choose the most optimal neutralizer, set its flow rate, and temperature of oil heating [30-32]. Also, the influence of the place where the reagent - neutralizer is introduced into degassed oil is studied.

\section{Conclusions}

The studies stated that the most effective results on the residual content of mercaptans in purified oil are achieved by adding the reagent-neutralizer to degassed oil after the second stage of separation. Also, the tests proved that water in oil affects the flow of reaction.

The action of the reagent-neutralizer takes place at the "oil-water" phase boundary. The dispersion contributes to the strengthening of mass interchange, reducing the response time of the neutralizer with oil. The mode of supply of the reagent-neutralizer should be continuous as when the supply of the reagent is ceased, the process of neutralizing hydrogen sulfide discontinues.

The laboratory tests made it possible to select the best neutralizer Desoulfon-SNPCH1200 , to determine its minimum specific consumption and the temperature of heating oil. The application of this reagent-neutralizer will allow doing the effective oil preparation at the loading point of the Borodino field.

The amount of Desoulfon-SNPCH-1200 needed to neutralize the mercaptans depends on their content in oil and the required degree of reduction. The usual proportion in processing is 4-5 ppm of Desoulfon-SNPCH-1200 at 1 ppm of mercaptans.

\section{Funding}

This research received no external funding.

\section{Acknowledgments}

This research has no acknowledgment.

\section{Conflicts of Interest}

The funders had no role in the design of the study, in the collection, analyses, or interpretation of data, in the writing of the manuscript, or in the decision to publish the results.

\section{References}

1. Feng, J.; Gao, S.; Fu, Q.; Chen, X.; Chen, X.; Han, D.; Cheng, J. Indirect source apportionment of methyl mercaptan using CMB and PMF models: a case study near a refining and petrochemical plant. Environ Sci Pollut Res Int. 2019, 26, 24305-24312. https://doi.org/10.1007/s11356-019-05728-4.

2. Zhou, J.; Jiang, Y. H.; Li, W. H.; Liu, X. Y. Kinetics and removal formula of methyl mercaptan by ethanol absorption without neglecting solute accumulation. J Environ Sci Health A Tox Hazard Subst Environ Eng. 2018, 53(14):1229-1234. https://doi.org/10.1080/10934529.2018.1528036.

3. Mortensen, P.; Grunwaldt, J.; Jensen, P.; Knudsen, K.; Jensen, A. A review of catalytic upgrading of bio-oil to engine fuels. Applied Catalysis A: General, 2018, 407(1-2), 1-19. doi: 10.1016/j.apcata.2018.08.046.

4. Copeland, A. Oil and gas. Australian Commodities, 2018, 15(3), 539-546. https://doi.org/10.4337/9781849809894.00010.

5. Zhou, J.; Jiang, Y. H.; Li, W. H.; Liu, X. Y. Comparison and analysis of several wet scrubbing solutions to remove methyl mercaptan. J Environ Sci Health A Tox Hazard Subst Environ Eng. 2018, 53(9):819-824. https://doi.org/10.1080/10934529.2018.1455340. 
6. He, D.; Zhang, L.; Zhao, Y.; Mei, Y.; Chen, D.; He, S.; Luo, Y. Recycling Spent Cr Adsorbents as Catalyst for Eliminating Methylmercaptan. Environ Sci Technol. 2018, 52(6):3669-3675. https://doi.org/10.1021/acs.est.7b06357.

7. Cola, P. R. Oil Gas. Publisher: Cambridge University Press, 2013, pp. 184-188. https://doi.org/10.1017/CBO9781139198264.012.

8. Mena, C. F.; Sampedro, C.; Martinez, P. E.; Paltan H. Remote Sensing of Oil Spills: linking community monitoring and satellite image procesing in the Ecuadorian Amazon. Reference Module in Earth Systems and Environmental Sciences. Comprehensive Remote Sensing, 2018, 9:144-158. https://doi.org/10.1016/B978-0-12-409548-9.10425-7.

9. Sharipov, A. Kh. Mercaptans from Gas Condensates and Crude Oils. Chemistry and Technology of Fuels and Oils, 2002, 38, 280-285. https://doi.org/10.1023/A:1020246204959.

10. Nizamov, K.; Bajmukhametov, M.; Murzagildin, Z.; Yaropolova, E.; Frolov, V. Divisions of oils into kinds in accordance with GOST R 51858-2002 for delivery to consumers of the Russian Federation and for export. Neftyanoe khozyaystvo - Oil Industry, 2018, 2, 98-100. ISSN: 00282448. (Russian)

11. Wang, Z.; Zhu, S.; Zhou, W.; Liu, H.; Hu, Y.; Guo, P.; Du, J.; Ren, J. Experimental research of condensate blockage and mitigating effect of gas injection. Petroleum, 2018, 4, 292-299. https://doi.org/10.1016/j.petlm.2018.03.008.

12. Zhang, M.; Ayala, L. A semi-analytical solution to compositional flow in liquid-rich gas plays. Fuel, 2018, 212, 274-292. doi.org/10.1016/j.fuel.2017.08.097.

13. Chatti, I.; Ghorbel, A.; Grange, P.; Colin. J. Oxidation of mercaptans in light oil sweetening by cobalt(II) phthalocyanine-hydrotalcite catalysts. Catalysis Today, 2002, 75(1-4), 113-117. https://doi.org/10.1016/S0920-5861(02)00051-2.

14. Baskar, G.; Kalavathy,G.; Aiswarya R,; Selvakumari A. Advances in bio-oil extraction from nondible oil seed and algal biomas. Advances in Eco-Fuels for a sustainable Environment, 2019, P. 187-210. https://doi.org/10.1016/B978-0-08-102728-8.00007-3.

15. Ehsaninejad, A.; Hajilary, N.; Tahmasebian, S.; Tohidi, B. Identification and Solutions for Flow Assurance Problems in Dew Pointing and Mercaptan Removal Unit in Phase $2 \& 3$. Proceedings of the 7th International Conference on Gas Hydrates (ICGH 2011), Edinburgh, Scotland, United Kingdom, July 17-21, 2011, p. 1200.

16. Seyedeyn-Azad, F.; Ghandy, A.; Aghamiri. S.; Khaleghian-Moghadam, R. Removal of mercaptans from light oil cuts using $\mathrm{Cu}(\mathrm{II})-\mathrm{Y}$ type Zeolite. Fuel Processing Technology, 2019, 90(12), 1459-1463. https://doi.org/10.1016/j.fuproc.2019.06.028.

17. Luis, P. Hybrid processes based on membrane technology. Fundamental Modeling of membane systems, 2018, P. 301-343. https://doi.org/10.1016/B978-0-12-813483-2.00008-3.

18. Ganguly, S.; Das, G.; Kumar, G.; Kumar, S.; Sain, B.; Garg. M. Catalytic oxidation of mercaptans in light oil sweetening: Kinetics and reactor design. Chemical Engineering Transactions, 2018, 32, 661-666. https://doi.org/10.3303/CET1332111.

19. De Jong, J.; Dowling. N.; Sargent. M.; Etheridge, A.; Saunders-Tack, A.; Fort, W. Effect of mercaptans and other organic sulfur species on high temperature corrosion in crude and condensate distillation units. NACE - International Corrosion Conference Series, 2007, pp. 075651-075657. ISSN: 03614409.

20. Aransiola, E. F.; Ehinmitola E.O.; Adebimpe, A. I.; Shittu, T D.; Solomon, B.O. Prospects of biodiesel feedstock as an effective ecofuel source and their challenges. Advances in Eco-Fuels for a Sustainable Environment, 2019, P. 53-87. https://doi.org/10.1016/B978-0-08-102728-8.00003-6.

21. Farshi, A.; Rabiei, Z. Kinetic Study for Oxidation of Existing Mercaptans in Kerosene Using Impregnated Activated Carbon with MEROX Catalyst in Alkaline Solution. Petroleum \& Coal, 2005, 47(1), 49-56.

22. Chebbi, A.; Hentati. D.; Cheffi. M.; Bouabdallah. R.; Choura. C.; Sayadi. S.; Chamkha M. Promising abilities of mercapto-degrading Staphylococcus capitis strain SH6 in both crude oil and waste motor oil as sole carbon and energy sources: its biosurfactant production and preliminary characterization. Journal of Chemical Technology and Biotechnology, 2018, 93(5), 1401-1412. https://doi.org/10.1002/jctb.5508.

23. Bulatov, A.; Goncharova. D.; Moskvin, L. Flow-injection photometric determination of mercaptans in light oil products with chromatomembrane extraction. Journal of Analytical Chemistry, 2006, 61(8), 801-803. https://doi.org/10.1134/S1061934806080156.

24. Li, J.; Li, X.; Liu, Y.; Zhang, J. Removal of mercaptans from light oils using ionic liquid-NaOH aqueous solution as extractants. Chinese Journal of Chemical Engineering, 2017, 25(2), 171-174. https://doi.org/10.1016/j.cjche.2016.08.031. 
25. Zhao, X.; Carroll, J.; Wu, Y. Acid Gas Injection for a Waste Stream with Heavy Hydrocarbons and Mercaptans. John Wiley and Sons, 2012, p. 143-152. https://doi.org/10.1002/9781118511138.ch10.

26. Eliseev, A.; Siniukov, A.; Shishkanov, K.; Pyatkov, E.; Eliseev, A. Utilization of pertraction and capillary condensation technologies for complex treatment of associated petroleum gas with microporous membranes. Neftyanoe Khozyaystvo - Oil Industry, 2018, 11, 51-57. https://doi.org/10.24887/0028-2448-2018-11-51-57. (Russian)

27. Kumar, S. et al. Comparison of PCCC Performance in Presence of Mercaptans and DBDS Sulfur in Transformer Oil Using $\varnothing$-t-N Technique. IJIREEICE, 2016, 4(1), 64-67. https://doi.org/10.17148/ijireeice.2016.4116.

28. Krylov, N.; Boksernan, A.; Stavrovsky, E.; Boksermant, A.; Filippov, V.; Filanovskii, V. Oil Extraction. CRC Press, 2019, P. 69-184. https://doi.org/10.1201/9780367810542-2.

29. Safarova, A. A. The solution to the optimization problem for the atmospheric unit of the technological complex of primary oil refining. Bulletin of science and education, 2019, 72(18), 29-33. (Russian)

30. Su, Z.; Tang, Y.; Ruan, H.; Wang, Y.; Wei, X. Experimental and modeling study of CO2-improved gas recovery in gas condensate reservoir. Petroleum 2017, 3, 87-95. https://doi.org/10.1016/j.petlm.2016.10.004.

31. Feng, W. Recovery enhancement at the later stage of supercritical condensate gas reservoir development via $\mathrm{CO} 2$ injection: a case study on Lian 4 fault block in the Fushan sag, Beibuwan Basin. Nat. Gas. Ind. B. 2017, 3, 460-466. https://doi.org/10.1016/j.ngib.2017.02.007.

32. Sawatdeenarunat, C.; Wangnai, C.; Songkasiri, W.; Panichnumsin P.; Saritpongteeraka K.; Boonsawang, P.; Khanal, S.; Chaiprapat, S. Biogas Production From Industrial Effluents. Biofuels: Alternative Feedstocks and Conversion Processes for the Production of Liquid and Gaseous Biofuels (Second Edition), 2019, P. 779-816. https://doi.org/10.1016/B978-0-12-816856-1.00032-4. 